\title{
A Set of Cytogenetic Markers Allows the Precise Identification of All A-Genome Chromosomes in Diploid and Polyploid Wheat
}

\author{
Ekaterina D. Badaeva ${ }^{a}$ b Alexandra V. Amosova ${ }^{b}$ Nikolay P. Goncharov ${ }^{c} d$ \\ Jiri Macas ${ }^{\text {e }}$ Alevtina S. Ruban ${ }^{f}$ Irina V. Grechishnikovab \\ Svyatoslav A. Zoshchuk ${ }^{\text {b }}$ Andreas Houben ${ }^{9}$ \\ a Vavilov Institute of General Genetics and b Engelhardt Institute of Molecular Biology, Russian Academy of Sciences, \\ Moscow, ' Institute of Cytology and Genetics, Siberian Branch of Russian Academy of Sciences, and d Novosibirsk \\ State Agrarian University, Novosibirsk, Russia; ' ${ }^{\mathrm{E}}$ Laboratory of Molecular Cytogenetics, Institute of Plant Molecular \\ Biology, Biology Centre AS CR, České Budéjovice, Czech Republic; ${ }^{\mathrm{f} D e p a r t m e n t ~ o f ~ G e n e t i c s, ~ B i o t e c h n o l o g y, ~ P l a n t ~}$ \\ Breeding and Seed Science, Russian State Agrarian University - Moscow Timiryazev Agricultural Academy, Moscow, \\ Russia; ${ }^{9}$ Chromosome Structure and Function Laboratory, Leibniz-Institute of Plant Genetics and Crop Plant \\ Research (IPK), Gatersleben, Germany
}

\section{Key Words}

A-genome evolution · Chromosome classification · Triticum

boeoticum · Triticum monococcum · Triticum urartu

\begin{abstract}
Karyotypes of 3 diploid wheat species containing different variants of the A-genome, Triticum boeoticum $\left(A^{b}\right)$, T. mono$\operatorname{coccum}\left(A^{b}\right)$, and T. urartu $\left(A^{u}\right)$, were examined using C-banding and FISH with DNA probes representing $5 \mathrm{~S}$ and $45 \mathrm{~S}$ rDNA families, the microsatellite sequences $G_{A} A_{n}$ and $G T_{n}$, the already known satellite sequences pSc119.2, Spelt52, Fat, pAs1, and pTa535, and a newly identified repeat called Aesp_SAT86. The C-banding patterns of the 3 species in general were similar; differences were observed in chromosomes $4 \mathrm{~A}$ and $6 \mathrm{~A}$. Besides 2 major $45 \mathrm{~S}$ rDNA loci on chromosomes $1 A$ and $5 A, 2$ minor polymorphic NORs were observed in the terminal part of $5 \mathrm{AL}$ and in the distal part of $6 \mathrm{AS}$ in all species. An additional minor locus was found in the distal part of $7 A^{b} L$ of $T$. boeoticum and T. monococcum, but not in T. urartu. Two 5S rDNA loci were observed in 1AS and 5AS.
\end{abstract}

The pTa535 probe displayed species- and chromosome-specific hybridization patterns, allowing complete chromosome identification and species discrimination. The distribution of pTa535 on the $\mathrm{A}^{\mathrm{u}}$-genome chromosomes was more similar to that on the A-genome chromosomes of $T$. dicoccoides and $T$. araraticum, thus confirming the origin of these genomes from $T$. urartu. The probe pAs1 allowed the identification of 4 chromosomes of T. urartu and 2 of $T$. boeoticum or T. monococcum. The Aesp_SAT86-derived patterns were polymorphic; main clusters were observed on chromosomes $1 A^{u}$ and $3 \mathrm{~A}^{\mathrm{u}}$ of $T$. urartu and chromosomes $3 \mathrm{~A}^{\mathrm{b}}$ and $6 \mathrm{~A}^{\mathrm{b}}$ of $T$. boeoticum. Thus, a set of probes, pTa535, pAs1, GAA ${ }_{n}$ and $\mathrm{GT}_{n}$, pTa71, pTa794, and Aesp_SAT86, proved to be most informative for the analysis of A-genomes in diploid and polyploid wheat species.

(c) 2015 S. Karger AG, Basel

The cultivated diploid wheat Triticum monococcum L. is one of the oldest domesticated crop species. Together with emmer and barley, einkorn constituted the principal

\section{KARGER 125}

C 2015 S. Karger AG, Base

$1424-8581 / 15 / 1461-0071 \$ 39.50 / 0$

E-Mail karger@karger.com

www.karger.com/cgr
Ekaterina D. Badaeva

Vavilov Institute of General Genetics

Russian Academy of Sciences

Gubkina Street 3, Moscow 11991 (Russia)

E-Mail katerinabadaeva@gmail.com 
grain stock that founded Neolithic agriculture and was the main element responsible for its successive spread [Feldman, 2001; Zohary and Hopf, 2001]. It has been assumed that T. monococcum was domesticated from its wild progenitor T. boeoticum Boiss in southeast Turkey, the Karacadağ mountain range [Heun et al., 1997]. Another wild diploid wheat species, T. urartu Tumanian ex Gandilyan, was the A-genome donor for polyploid durum and bread wheat as well as for the species of the Timopheevi group [Dvořák et al., 1993; Ling et al., 2013]. Natural hybridization of T. timopheevii (Zhuk.) Zhuk. with cultivated einkorn T. monococcum gave rise to T. zhukovskyi Menabde et Ericzjan, a new hexaploid wheat species with a unique genome constitution [Bowden, 1959; Tavrin, 1964; Upadhia and Swaminathan, 1969]. Although T. monococcum is not cultivated anymore, it is used in wheat breeding as a source of disease resistance genes, high carotenoid content, and other agronomically important characters [Damania et al., 1998; Singh et al., 2008].

Wild einkorns T. urartu $\left(\mathrm{A}^{\mathrm{u}}\right)$ and T. boeoticum $\left(\mathrm{A}^{\mathrm{b}}\right)$ share similar morphological characters [Dorofeev et al., 1979]. They carry closely related genomes that probably diverged $\sim 0.5-1$ mya [Huang et al., 2002]. Genetically, $T$. monococcum is similar to T. boeoticum [Konarev, 1980], and many taxonomists treat it as a subspecies of T. monococcum [Van Slageren, 1994]. Genomes of these species can be discriminated using immunological, biochemical, and molecular markers [Jaaska, 1980; Brandolini et al., 2006; Badaeva et al., 2010a; Konovalov et al., 2010]. However, they are karyotypically similar and have similar Giemsa C-banding patterns [Kuz'menko et al., 1987; Friebe and Gill, 1996]. No reliable markers permitting unequivocal species identification can be provided using C-banding.

An alternative method of chromosome analysis is FISH, which allows direct localization of DNA sequences on chromosomes. FISH in plants often employs probes containing conservative high-copy sequences, like $5 \mathrm{~S}$ and 45S ribosomal RNA genes [Gerlach and Bedbrook, 1979; Gerlach and Dyer, 1980]. The number and relative position of $5 \mathrm{~S}$ and $45 \mathrm{~S}$ rDNA loci in the Triticeae species was shown to be a conservative feature of genomes or genome groups. Therefore, these markers are often used in phylogenetic studies, in the analysis of intra- and interspecific divergence, and in the elucidation of the origin of polyploid species [Badaeva et al., 1996a, 2002, 2004, 2010b; Taketa et al., 1999, 2001, 2005]. Karyotype evolution is also associated with alterations and reorganization of other repetitive sequences [Kubis et al., 1998]. Localization of some families of tandem repeats in plant chromosomes was found to coincide with the position of C-bands
[Bedbrook et al., 1980; Pedersen and Langridge, 1997; Cuadrado et al., 2000].

Chromosomes of diploid wheats possess only few small C-bands [Kuz'menko et al., 1987; Friebe et al., 1990; Friebe and Gill, 1996]. Therefore, one may expect that the 'classical' marker for a Giemsa-positive region, the $\mathrm{GAA}_{n}$ microsatellite [Pedersen and Langridge, 1997; Cuadrado et al., 2000; Cuadrado et al., 2008], will be non-informative for their analysis. Indeed, application of microsatellite probes to $T$. monococcum revealed small signals on only chromosomes $2 \mathrm{~A}^{\mathrm{m}}$ and $6 \mathrm{~A}^{\mathrm{m}}$ [Megyeri et al., 2012]. Although clear $\mathrm{GAA}_{\mathrm{n}}$ signals have been detected on several A-genome chromosomes of polyploid wheat [Pedersen and Langridge, 1997; Kubaláková et al., 2005], they could have emerged as a result of species-specific translocations with B-genome chromosomes [Liu et al., 1992]. Probe pSc119.2 [Bedbrook et al., 1980], which is frequently employed for examination of polyploid wheat, also proved to be little informative for the analysis of Agenomes [Schneider et al., 2003; Megyeri et al., 2012].

The Afa DNA probe could be useful for chromosome identification of diploid wheats and discrimination between $\mathrm{A}^{\mathrm{b}}$ - and $\mathrm{A}^{\mathrm{u}}$-genome types. The Afa-type probes are also used for chromosome identification of polyploid wheat [Mukai et al., 1993; Pedersen and Langridge, 1997; Schneider et al., 2003; Kubaláková et al., 2005] and Aegilops species [Rayburn and Gill, 1986a, 1987; Badaeva et al., 1996b; Bardsley et al., 1999] as well as in phylogenetic studies of other cereals [Taketa et al., 2000]. Afa allowed the identification of most chromosomes of cultivated einkorn [Megyeri et al., 2012] and some A-genome chromosomes of durum and bread wheat [Schneider et al., 2003; Sepsi et al., 2008]. The karyotype of T. urartu, however, has not been studied using this probe.

More recently, several novel repeat families were isolated from the bread wheat genome [Komuro et al., 2013]. The most informative labelling patterns were generated by pTa535, pTa-713, and pT-86 (homolog of pSc119 sequence). Among them, the probe $\mathrm{pTa} 535$ produced the highest number of signals on the A-genome chromosomes, and labelling patterns were chromosome-specific. This clone is a 342-bp tandemly repeated DNA sequence, showing $\sim 80 \%$ homology with clone pTa173, a member of the Afa-family [Komuro et al., 2013].

The aim of our study was the analysis of 3 diploid wheat species using C-banding and FISH with different families of tandemly repeated sequences to develop a set of informative probes for precise chromosome identification, allowing the discrimination between species and the analysis of chromosome evolution in the genus Triticum $\mathrm{L}$.
72

Cytogenet Genome Res 2015;146:71-79 DOI: $10.1159 / 000433458$
Badaeva et al. 


\section{Materials and Methods}

\section{Plant Material}

The list of accessions of T. boeoticum, T. monococcum, and T. urartu used in our study is shown in online supplementary table 1 (see www.karger.com/doi/10.1159/000433458 for all online suppl. material). The materials were provided by Dr. O.P. Mitrofanova (VIR, St. Peterburg, Russia), Dr. H. Bockelman (USDA-ARS, Aberdeen, Idaho, USA); Dr. J. Valkoun (ICARDA, Aleppo, Syria), Dr. T. Kawahara (Kyoto University, Kyoto, Japan), Dr. M. Feldman (Weizmann Institute of Science, Rehovot, Israel), Drs. E.A. Nazarova and A.G. Gukasyan (Institute of Botany, National Academy of Sciences of Armenia, Erevan, Armenia), Dr. B. Kilian (IPK, Gatersleben, Germany), and Dr. N.K. Aminov (Institute of Genetic Resources of Azerbaijan, Baku, Azerbaijan).

\section{DNA Probes}

The following probes were used for FISH:

(1) pTa71 - a 9-kb-long sequence of common wheat encoding $18 \mathrm{~S}, 5.8 \mathrm{~S}$, and $26 \mathrm{~S}$ rRNA genes including spacers [Gerlach and Bedbrook, 1979]

(2) pTa794 - a 420-bp-long sequence of wheat containing the 5S rRNA gene and intergenic spacer [Gerlach and Dyer, 1980]

(3) pAs1 - a 1-kb fragment derived from Ae. tauschii and belonging to the Afa family [Rayburn and Gill, 1986b]

(4) $\mathrm{pSc} 119.2$ - a 120-bp-long sequence isolated from rye [Bedbrook et al., 1980]

These probes were labeled with FITC (fluorescein-12-dUTP, Roche, Germany) or biotin (biotin-16-dUTP, Roche, Germany) by nick translation according to the manufacturer's instruction.

(5) Spelt-52 (homolog of pAesKB52), a 276-bp-long sequence was labeled with fluorescein-12-dUTP by PCR with the primer pair (5'-TGA AAT ACT TGC ACA CAA ACC-3'; $5^{\prime}$-GTT AGT TCT GAG TGA ATT GCC-3') using Ae. speltoides genomic DNA as template, as described in Salina et al. [2004].

(6) Fat, a 460-bp-long sequence, was labeled with fluorescein12-dUTP by PCR with the primer pair ( $5^{\prime}$-GGG GAG CTT CTC ACA ACA AGC- $3^{\prime} ; 5^{\prime}$-TAT TTA CCA CGG CAT GTC GGG-3') using genomic DNA of bread wheat as template, as described in Badaeva et al. [2010c].

(7) Aesp_SAT86 is a new satellite family with a monomer length of 86 bp identified in Ae. speltoides genomic DNA via in silico cluster analysis [Novak et al., 2010]. It shows 91-94\% similarity to the wheat repeat pTa-713 described in Komuro et al. [2013]. The probe was labeled with fluorescein-12-dUTP or biotin-16-dUTP by PCR with the primer pair $\left(5^{\prime}\right.$-AGC ACG TGA CAC CAT TGC-3'; 5'-GAC TCG CGT TAC GCT AAG ACA-3') using genomic DNA of Ae. speltoides as template.

(8) pTa535-1 was used as a 5' 6-carboxyfluorescein (6-FAM) or 6-carboxytetramethylrhodamine (TAMRA) end-labelled (MWG, Germany) oligo probe ( $5^{\prime}$-AAA AAC TTG ACG CAC GTC ACG TAC AAA TTG GAC AAA CTC TTT CGG AGT ATC AGG GTT TC-3') [Komuro et al., 2013; Tang et al., 2014].

(9) Microsatellite (CTT) 10 was directly labelled with 5/6 sulforhodamine 101PEG3_azide by click chemistry (Baseclick, Germany); the complementary (GAA) 9 oligo probe, labelled at the $3^{\prime}$ end with fluorescein-12-dUTP, was synthesized in the laboratory of biological microchips at the Institute of Molecular Biology, Moscow, Russia.

Cytogenetic Markers for Chromosome

Identification of Einkorn Wheat
(10) The oligo- $(\mathrm{GTT})_{9}$ probe, labelled at the $3^{\prime}$ end with fluorescein-12-dUTP, was synthesized in the laboratory of biological microchips at the Institute of Molecular Biology, Moscow, Russia.

Giemsa C-Banding Method

The C-banding method described in Badaeva et al. [1994] was used for analysis. Chromosomes were classified according to the nomenclature suggested in Friebe and Gill [1996] and Friebe et al. [1990].

\section{Fluorescence in situ Hybridization}

FISH was carried out according to a standard protocol [Badaeva et al., 1996b] with minor modifications [Zoshchuk et al., 2007]. The probes labelled with fluorescein were detected using anti-fluorescein/Oregon green, rabbit IgG fraction, Alexa Fluor 488 conjugate (Molecular Probes, USA). Biotin was detected with streptavidin-Cy3 (Amersham Pharmacia Biotech, USA). The slides were counter-stained with DAPI (4',6-diamidino-2-phenylindole) in Vectashield mounting media (Vector laboratories, Peterborough, UK) and analyzed using a Zeiss Imager D-1 microscope. Selected metaphase cells were captured with an AxioCam HRm digital camera using software AxioVision, version 4.6. Images were processed in Adobe Photoshop, version CS5 (Adobe Systems, Edinburgh, UK). The FISH painted chromosomes were classified according to Komuro et al. [2013] and Megyeri et al. [2012].

\section{Results and Discussion}

\section{Giemsa C-Banding Analysis of T. boeoticum,}

T. monococcum, and T. urartu Karyotypes

The karyotypes of 8 accessions of T. boeoticum, 2 of T. monococcum, and 7 of T. urartu were analyzed by Cbanding (online suppl. table S1). All species were characterized by few Giemsa-positive bands in accordance with previous observations [Kuz'menko et al., 1987; Friebe et al., 1990; Friebe and Gill, 1996]. Most C-bands were small and localized in interstitial chromosome regions (online suppl. figs. S1, S2). Bands on chromosomes 1A and 5A adjacent to NORs were usually the largest. C-banding patterns of T. boeoticum chromosomes were virtually identical to those of T. monococcum (online suppl. fig. S2) but differed from T. urartu (online suppl. fig. S1) and were similar to those described earlier [Kuz'menko et al., 1987; Friebe et al., 1990; Friebe and Gill, 1996]. Most obvious differences between the $\mathrm{A}^{\mathrm{u}}$ and $\mathrm{A}^{\mathrm{b}}$ genomes were observed in the C-banding patterns of chromosomes $4 \mathrm{~A}$ and $6 \mathrm{~A}$. In particular, chromosome $4 \mathrm{~A}^{\mathrm{u}}$ of T. urartu carried one weak interstitial band in the proximal part of the short arm (online suppl. fig. S1), whereas chromosome $4 \mathrm{~A}^{\mathrm{b}}$ of $T$. boeoticum/T. monococcum contained 2 weak Cbands in the short arm and 1 distinct band adjacent to the pericentromeric region in the long arm (fig. 1e, online suppl. fig. S2).We failed to find any constant C-bands on 


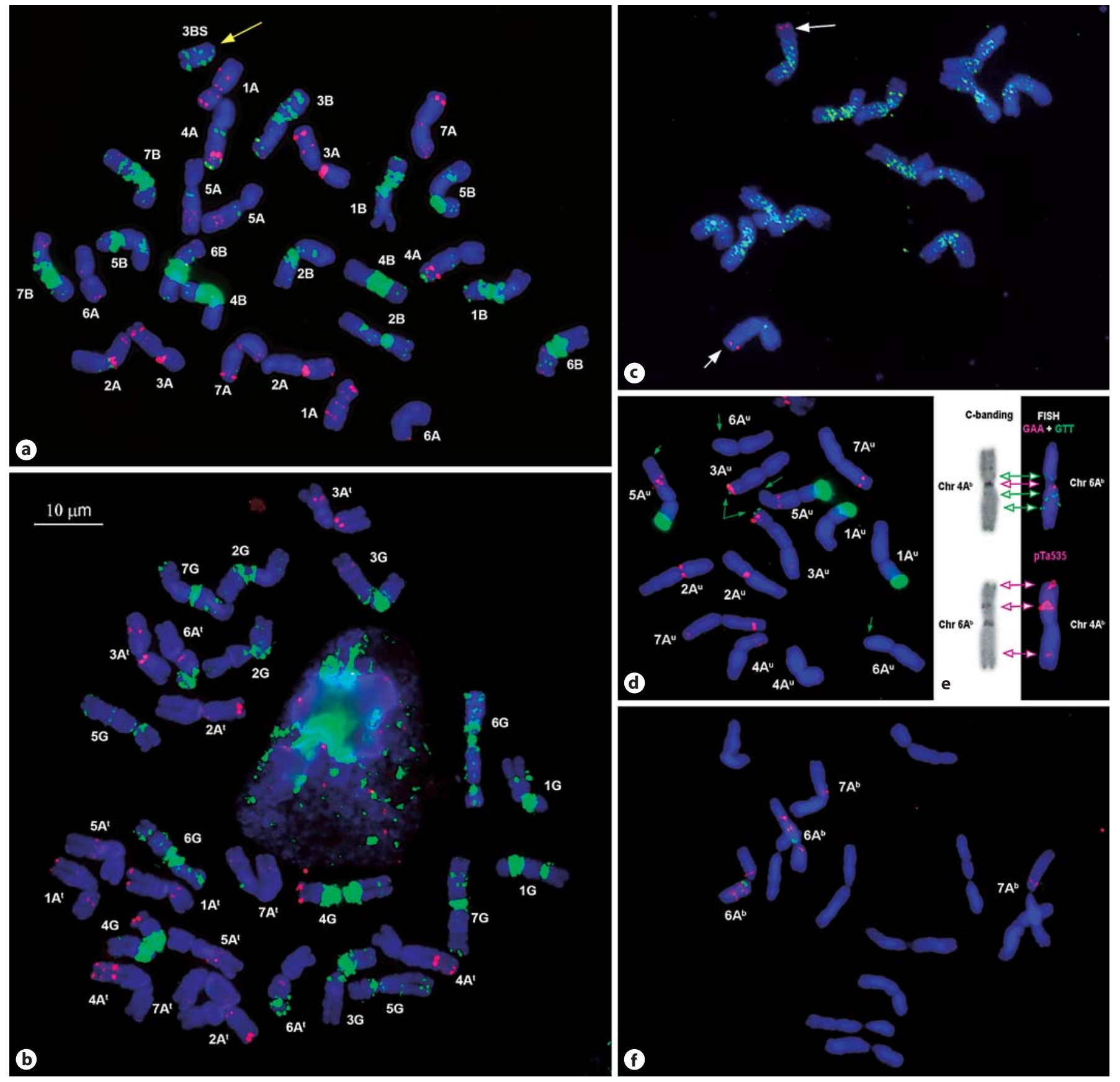

Fig. 1. Distribution of different families of repetitive DNA on selected metaphase chromosomes of diploid and tetraploid wheat species (chromosomes are designated according to the genetic nomenclature). a, b T. dicoccoides (KU 8836A, Iraq; a) and T. araraticum (KU 8926, Turkey; b) hybridized with pTa535 (red) and $\mathrm{GAA}_{\mathrm{n}}$ (green) probes. The yellow arrow points to a spontaneous telocentric 3BS chromosome. c T. boeoticum (K-25811) hybridized with pSc119.2 (red, indicated with white arrows) and Fat (green) probes. d T. urartu (TA 831) hybridized with pTa71 (green) and pTa535 (red) probes. Green arrows show minor NORs detected in the subtelomeric region of $3 \mathrm{~A}^{\mathrm{u}} \mathrm{L}, 5 \mathrm{~A}^{\mathrm{u}} \mathrm{L}$, and $6 \mathrm{~A}^{\mathrm{u}} \mathrm{S}$. e Comparison of C-banding (left) and FISH (right) patterns of chromosomes $4 \mathrm{~A}^{\mathrm{b}}$ and $6 \mathrm{~A}^{\mathrm{b}}$ of T. monococcum. C-banded chromosomes are classified according to Friebe and Gill [1996]; FISH-labelled chromosomes are classified according to Megyeri et al. [2012] and with consideration of hybridization patterns of the $45 \mathrm{~S}$ rDNA probe. Positions of C-bands and corresponding $\mathrm{GAA}_{\mathrm{n}}$ and $\mathrm{GTT}_{\mathrm{n}}$ or $\mathrm{pAs} 1$ sites are indicated with arrows. f T. monococcum (MG 4278) hybridized with $\mathrm{GAA}_{\mathrm{n}}$ (green) and $\mathrm{GTT}_{\mathrm{n}}$ (red) probes. 
chromosome $6 \mathrm{~A}^{\mathrm{u}}$ of $T$. urartu, while $6 \mathrm{~A}^{\mathrm{b}}$ of $T$. boeoticum always carried clear C-bands in the middle and sometimes in a distal region of the short arm.

C-banding patterns of T. urartu satellite chromosomes were polymorphic. Chromosome $1 \mathrm{~A}^{\mathrm{u}}$ often possessed Cbands in the proximal region of the short arm, and Cbands located in the middle of the long arm were characteristic for chromosome $5 \mathrm{~A}^{\mathrm{u}}$. These bands, however, were present in some but not all accessions studied. Chromosome $5 \mathrm{~A}^{\mathrm{b}}$ can be discriminated from $1 \mathrm{~A}^{\mathrm{b}}$ by the presence of a pair of weak $\mathrm{C}$-bands in the distal region of the long arm.

Chromosomes assigned to homoeologous groups 2, 3, and 7 in all einkorn species possessed only small C-bands located in similar positions. Thus, C-banding does not permit the precise identification of all chromosomes of diploid wheat species, though it allowed the discrimination of T. urartu from T. boeoticum based on the presence or absence of marker C-bands on chromosomes $4 \mathrm{~A}$ and $6 \mathrm{~A}$.

\section{Distribution of Highly Repetitive DNA Sequence on Chromosomes of Diploid Wheats}

All DNA probes tested in our study generated signals on chromosomes of diploid wheat; however, not all probes in diagnostic patterns. Thus, only small signals of pSc119.2 (fig. 1c) and Spelt-52 probes were rarely observed in subtelomeric regions of one chromosome pair. These chromosomes probably belong to homoeologous group 2 as the same probes were mapped to the short (Spelt-52) and long (pSc119.2) arms of chromosome 2A of tetraploid wheat species [Salina et al., 2006a; Zoshchuk et al., 2007]. Although the Fat probe produced many signals on all chromosomes of einkorn species, their distribution was not specific for a particular chromosome or genome type (fig. 1c). Owing to these features, these 3 sequences were considered less informative for the identification of A-genome chromosomes.

Satellite Sequence pTa535. Hybridization of common wheat chromosomes with pTa535 generated signals mainly on the A- and D-genome chromosomes and, in combination with other probes, allowed the identification of all common wheat chromosomes [Komuro et al., 2013]. Hybridization of oligo-pTa535-1 probe to chromosomes of all 3 einkorn species revealed clear and highly specific labelling patterns (fig. 2). All chromosomes except $6 \mathrm{~A}^{\mathrm{b}}$ carried $1-4$ hybridization sites in chromosomespecific positions, although some intraspecific variation in signal localization and intensity has been observed (fig. 2, polymorphic sites are indicated by an asterisk).
Chromosomes belonging to homoeologous groups 1,3 , and 7 in different species had similar labelling patterns, and intraspecific differences were found for chromosomes of groups 2, 4, 5, and 6. Noteworthy, distribution of pTa 535 on the $\mathrm{A}^{\mathrm{u}}$ genome chromosomes was very similar with that on $T$. dicoccoides (fig. 1a), T. aestivum [Komuro et al., 2013], and T. araraticum (fig. 1b) chromosomes, thus confirming the origin of their A-genomes from T. urartu. This similarity allowed us to apply the chromosome nomenclature developed for common wheat A-genome chromosomes [Komuro et al., 2013] for the classification of the A-genome chromosomes of diploid wheats. Intraspecific differences in the distribution of pTa535 on chromosomes $3 \mathrm{~A}^{\mathrm{u}}-3 \mathrm{~A}^{\mathrm{t}}, 4 \mathrm{~A}^{\mathrm{u}}-4 \mathrm{~A}-4 \mathrm{~A}^{\mathrm{t}}$ or $6 \mathrm{~A}^{\mathrm{u}}-6 \mathrm{~A}^{\mathrm{t}}$ can be caused by species-specific translocations identified in 2 allopolyploid wheat species [Jiang and Gill, 1994a; Liu et al., 1992; Salina et al., 2006b].

Hybridization patterns of pTa535 on T. boeoticum and T. monococcum chromosomes were similar. Some differences between these species observed in the probe distribution on chromosome $2 \mathrm{~A}^{\mathrm{b}}$ can be due to intraspecific polymorphisms and the small number of accessions studied.

Afa-Family. According to Megyeri et al. [2012], the wheat-derived $A f a$ repeat probe allowed the identification of 5 out of 7 chromosomes of cultivated einkorn. The pAs1 clone isolated from Ae. tauschii [Rayburn and Gill, 1986b] belongs to the same Afa family [Nagaki et al., 1995]. Hybridization patterns of pAs1 on T. monococcum chromosomes obtained in our work (fig. 2) only partially corresponded to those published in Megyeri et al. [2012]. Differences of hybridization patterns produced by closely related probes isolated from different species can be due to the divergence of their nucleotide sequences. In $T$. monococcum, 2 weak pAs1 signals were found in the opposite arms of $6 \mathrm{~A}^{\mathrm{b}}$, which were not labelled with pTa535. The strongest pAs1 signals were detected on chromosomes $4 \mathrm{~A}^{\mathrm{b}}$ and $7 \mathrm{~A}^{\mathrm{b}}$, and they did not overlap with $\mathrm{pTa} 535$ hybridization sites (fig. 2).

Up to 6 pAs 1 hybridization sites have been detected in T. urartu; among them the largest ones ( $2 \mathrm{~A}^{\mathrm{u} S}$ and $\left.5 \mathrm{~A}^{\mathrm{u}} \mathrm{L}\right)$ were polymorphic (fig. 2). Localization of pAs1 on chromosomes $7 \mathrm{~A}^{\mathrm{u}} \mathrm{L}$ and $4 \mathrm{~A}^{\mathrm{u}} \mathrm{S}$ was similar to that in T. boeoticum, while chromosome $6 \mathrm{~A}^{\mathrm{u}}$ carried 2 clear pAs1 sites in the long arm.

Microsatellites $G A A_{n}$ and $G T T_{n}$. Hybridization of the $\mathrm{GAA}_{\mathrm{n}}$ probe revealed only very weak signals on chromosomes $1 \mathrm{~A}^{\mathrm{u}}$ and $5 \mathrm{~A}^{\mathrm{u}}$ of $T$. urartu (fig. 2). T. monococcum contained only 1 strong signal in the pericentromeric region of $6 \mathrm{~A}^{\mathrm{b}}$ (figs. 1f, 2), and the additional hybridization 


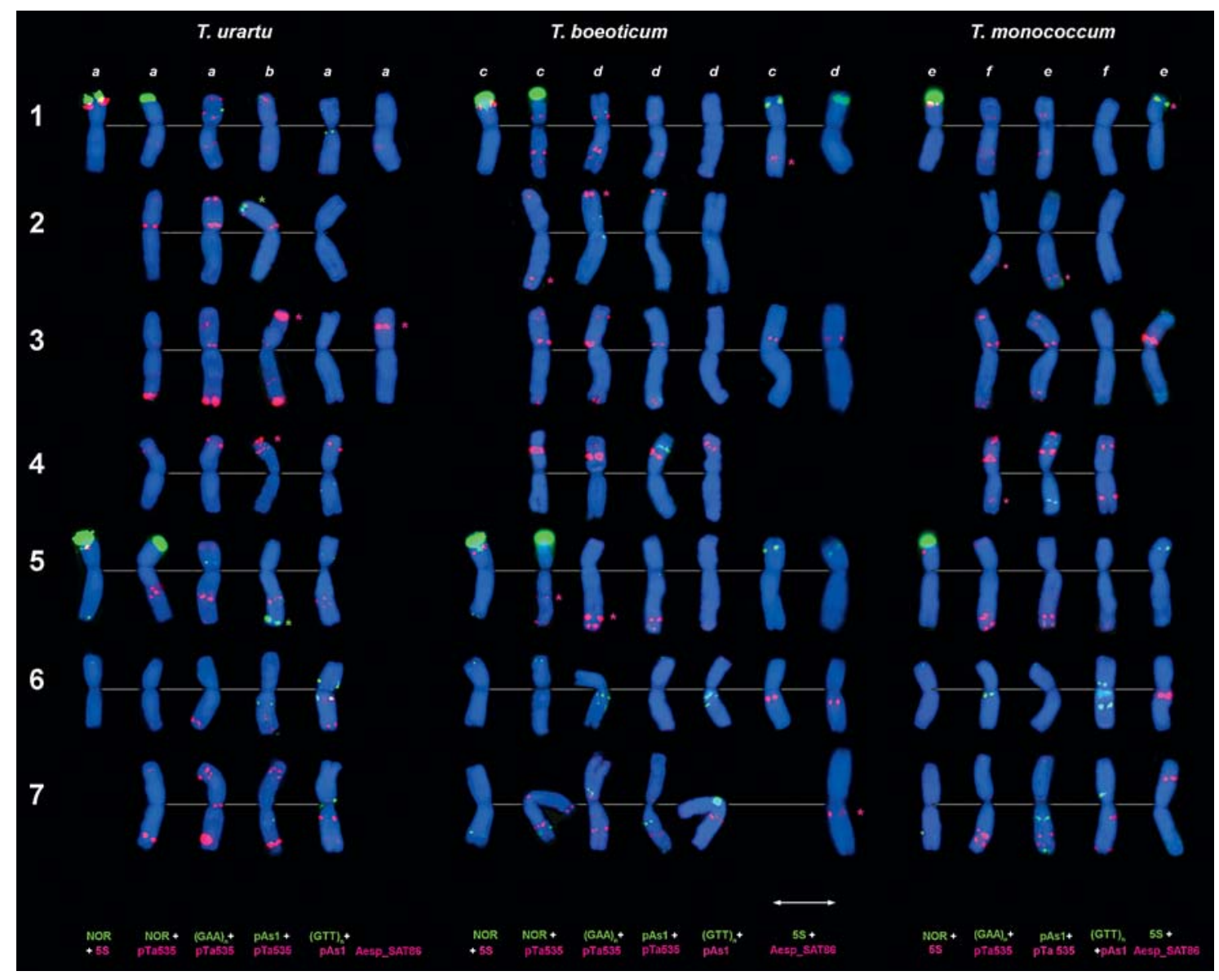

Fig. 2. Comparison of the distribution of different types of repetitive DNA on chromosomes of 3 diploid wheat species: T. urartu $(\mathrm{a}=\mathrm{TA} 787, \mathrm{~b}=\mathrm{TA} 831)$, T. boeoticum $(\mathrm{c}=11-60 ; \mathrm{d}=\mathrm{PI} 554546)$, and T. monococcum $(\mathrm{e}=$ MG 4278, f = PI 428282). Chromosomes are assigned to homoeologous groups 1-7. Probe combinations are shown at the bottom of the figure. Hybridization sites showing intraspecific polymorphisms are indicated with an asterisk in the color corresponding to the respective probe.

site was found on chromosome $7 \mathrm{~A}^{\mathrm{b}}$ of both studied accessions of T. boeoticum. In contrast to Megyeri et al. [2012], we have not revealed a telomeric $\mathrm{GAA}_{n}$ signal on chromosome $2 \mathrm{~A}^{\mathrm{b}}$, which can be due to an intraspecific polymorphism.

Chromosomal distribution of $\mathrm{GTT}_{\mathrm{n}}$ and $\mathrm{GAA}_{\mathrm{n}}$ signals differed between the chromosomes of diploid wheat species. In T. urartu, 2 very small $\mathrm{GTT}_{\mathrm{n}}$ signals were detected on the short and long arms of chromosome $1 \mathrm{~A}^{\mathrm{u}}$, in the proximal third of $5 \mathrm{~A}^{\mathrm{u} S}$ and proximal part of $4 \mathrm{~A}^{\mathrm{u}} \mathrm{L}$ (fig. 2). Several signals with higher intensities were observed in both arms of $6 \mathrm{~A}^{\mathrm{u}}$ and in the pericentromeric region of $7 \mathrm{~A}^{\mathrm{u}}$. $\mathrm{A}^{\mathrm{b}}$-genome species showed a similar signal distribution on chromosomes $6 \mathrm{~A}^{\mathrm{b}}$ and $7 \mathrm{~A}^{\mathrm{b}}$, but all smaller sites found in the T. urartu genome were absent.
Comparison of the hybridization patterns of $\mathrm{GAA}_{n}$ and $\mathrm{GTT}_{\mathrm{n}}$ microsatellite probes and of the $\mathrm{pAs} 1$ sequences on T. monococcum chromosomes with their C-banding patterns raised the question, whether the classification of $4 \mathrm{~A}^{\mathrm{b}}$ and $6 \mathrm{~A}^{\mathrm{b}}$ chromosomes should be reconsidered. The identity of $4 \mathrm{~A}^{\mathrm{b}}$ of $T$. boeoticum was established in a 29 -chromosome wheat form, in which chromosome $4 \mathrm{~A}^{\mathrm{b}}$ spontaneously substituted $4 \mathrm{~A}$ of T. durum [Friebe et al., 1990]. At the same time, the C-banded chromosome $4 \mathrm{~A}^{\mathrm{b}}$ is more similar with the FISH-labelled chromosome $6 \mathrm{~A}^{\mathrm{b}}$ and vice versa (fig. 1e). As demonstrated by Cuadrado et al. [2000], the positions of C-bands on wheat chromosomes coincide with the location of $\mathrm{GAA}_{n}$ or $\mathrm{GTT}_{n}$ microsatellite sequences. The distribution of $\mathrm{C}$-bands on the D-genome chromosomes of Triticum and Aegilops often 
overlaps with the distribution of pAs1 hybridization sites [Friebe et al., 1992]. In addition, T. monococcum carries a minor pTa71 site ( $45 \mathrm{~S}$ rDNA locus) on $6 \mathrm{~A}^{\mathrm{b}} \mathrm{S}$, which could be the remnant of an ancient, inactive NOR locus derived from a common progenitor of the Triticeae. Based on these facts, we suggest that the classification of C-banded chromosomes should be verified.

Satellite Sequence Aesp_SAT86. Hybridization of the Aesp_SAT86 probe on T. urartu chromosomes revealed 1-2 large signals located in the middle of $1 \mathrm{~A}^{\mathrm{u}} \mathrm{L}$ and in $3 \mathrm{~A}^{\mathrm{u}} \mathrm{S}$, the latter one being polymorphic between the accessions. Three large clusters have been detected in $T$. monococcum chromosomes: in $3 \mathrm{~A}^{\mathrm{b} S}, 6 \mathrm{~A}^{\mathrm{b}} \mathrm{L}$ close to the centromere, and in $7 \mathrm{~A}^{\mathrm{b}} \mathrm{L}$ (fig. 2). Two very small signals were observed in pericentromeric regions of chromosome $7 \mathrm{~A}^{\mathrm{b}}$ and in the short arm of chromosome $1 \mathrm{~A}^{\mathrm{b}}$, close to the $5 \mathrm{~S}$ rDNA site. The labelling pattern of $T$. boeoticum chromosomes was similar to that of T. monococcum, although we found a difference between the accessions in signal distribution. Only 2 loci on $3 \mathrm{~A}^{\mathrm{b}} \mathrm{S}$ and $6 \mathrm{~A}^{\mathrm{b}} \mathrm{L}$ were constant. Accession PI 554546 contained an additional site in the middle of $1 \mathrm{~A}^{\mathrm{b}} \mathrm{L}$, similar to chromosome $1 \mathrm{~A}^{\mathrm{u}}$ of T. urartu. Small pericentromeric signals were found on chromosome $7 \mathrm{~A}^{\mathrm{b}}$ of accession 11-60. Based on these results, we suggest that Aesp_SAT86 can be used in the analysis of einkorn for species discrimination and identification of particular chromosomes.

Localization of $5 S$ and 18S-5.8S-26S rDNA Loci on Chromosomes of Diploid Wheats. Mapping of the ribosomal RNA gene probes pTa71 (18S-5.8S-26S rDNA or NOR) and pTa794 (5S rDNA) on chromosomes of 3 diploid wheat species revealed 2 major $\mathrm{rDNA}$ loci with equal or slightly different sizes on chromosomes $1 \mathrm{~A}$ and $5 \mathrm{~A}$, which is in accordance with previous observations [Jiang and Gill, 1994b; Dubcovsky and Dvořák, 1995; Megyeri et al., 2012]. In some accessions, however, we observed a significant size reduction at one of the loci (T. boeoticum - K-20741, T. urartu - PI 428311, K-58495, online suppl. fig. S3a) up to a complete locus loss $\left(5 \mathrm{~A}^{\mathrm{m}}\right.$ in T. boeoticum, K-40118 from Iraq, online suppl. fig. S3c).

Besides major NORs, the karyotypes of most accessions showed 1-3 pairs of minor 45S rDNA sites (online suppl. fig. S3, online suppl. table S2). One of these, described earlier as Nor-A7 by Jiang and Gill [1994b], was found in the subterminal region of chromosome 5AL. The second minor NOR, designated NOR-Ax [Jiang and Gill, 1994b; Dubcovsky and Dvořák, 1995], was located in a distal part of $7 \mathrm{~A}^{\mathrm{b}} \mathrm{L}$. This locus was found in T. boeoticum and T. monococcum only (fig. 2, online suppl. fig. S3a-d, h, online suppl. table S2). The third, smallest $45 \mathrm{~S}$ rDNA

Cytogenetic Markers for Chromosome

Identification of Einkorn Wheat locus, designated NOR-Ay [Jiang and Gill, 1994b], was detected in the distal region of chromosome 6AS, thus confirming the assumption of Dubcovsky and Dvořak [1995]. The NOR-Ay locus could have derived as a result of a significant reduction of $45 \mathrm{~S}$ rDNA copy number in the respective locus on group 6 chromosomes that has probably occurred in a common ancestral form of einkorn species. This locus was found in all studied accessions of T. boeoticum/T. monococcum and in approximately half of $T$. urartu accessions (fig. 2, online suppl. fig. S3e, g, online suppl. table S2). Intraspecific heterogeneity could explain the fact that other authors [Jiang and Gill, 1994b] have not revealed 45S rDNA loci on chromosome $6 \mathrm{~A}^{\mathrm{u}}$ of $T$. urartu.

Two $5 \mathrm{~S}$ rDNA loci with equal to sharply different sizes were located in the short arms of $1 \mathrm{~A}$ and $5 \mathrm{~A}$ distal to the major NORs (fig. 2, online suppl. fig. S3). The $5 \mathrm{~S}$ rDNA locus was absent on chromosome $5 \mathrm{~A}^{\mathrm{b}}$ of $T$. boeoticum accession K-61600 from Greece (online suppl. fig. S3h). In the majority of T. boeoticum/T. monococcum accessions the size of $5 \mathrm{~S}$ rDNA loci on chromosomes $1 \mathrm{~A}^{\mathrm{b}}$ and $5 \mathrm{~A}^{\mathrm{b}}$ were nearly the same (online suppl. fig. S3a, c, d) or the locus on $1 \mathrm{~A}^{\mathrm{b}}$ was slightly larger (online suppl. fig. S3b). By contrast, nearly half of T. urartu accessions carried a significantly larger $5 \mathrm{~S}$ rDNA site on chromosome $1 \mathrm{~A}^{\mathrm{u}}$ (online suppl. fig. S3e), and in only few accessions both loci had approximately the same sizes (online suppl. fig. S3e).

\section{Conclusions}

Application of different methods of chromosome analysis of einkorn wheat shows that FISH with particular probe combinations exhibits obvious advantages over the C-banding technique with respect to chromosome identification and discrimination between species with different genome constitutions. Among 10 DNA probes tested, the best informative probe was pTa535 (which generates marker signals on all chromosomes allowing chromosome identification and species discrimination). Chromosomes $1 \mathrm{~A}$ and $5 \mathrm{~A}$ can be identified also by using either one of the rDNA probes, while $6 \mathrm{~A}$ and $7 \mathrm{~A}^{\mathrm{b}}$ are marked by the presence of minor $45 \mathrm{~S}$ rDNA loci. The pAs 1 clone can be applied as an additional probe specific for chromosomes 4A, 6A, and 7A. Similarly, microsatellite sequences $\mathrm{GAA}_{\mathrm{n}}$ and $\mathrm{GTT}_{\mathrm{n}}$ will be useful for the detection of chromosomes 6A and 7A. Although DNA probes pSc119.2 and Spelt52 were considered not informative for the analysis of einkorn wheat genomes, they can be 
utilized for the identification of chromosome $2 \mathrm{~A}$ in some accessions. Comparison of C-banding and FISH data revealed a conflict between these systems in the classification of $4 \mathrm{~A}$ and $6 \mathrm{~A}$ chromosomes. Similarity of pTa535 FISH patterns on the $\mathrm{A}$ and $\mathrm{A}^{\mathrm{t}}$ genome chromosomes of tetraploid T. dicoccoides and T. araraticum with the $\mathrm{A}^{\mathrm{u}}$ genome chromosomes of $T$. urartu further confirmed the origin of all polyploid wheat from this einkorn species. Some differences observed between chromosomes of diploid and polyploid species could be caused by speciesspecific translocations that occurred during the formation of primary wheat allotetraploids.

\section{Acknowledgements}

We thank Dr. B. Kilian [Leibniz Institute of Plant Genetics and Crop Plant Research (IPK), Genebank/Genome Diversity, Germany], Dr. M. Feldman (Weizmann Institute of Science, Rehovot, Israel), Drs. E.A. Nazarova and A.G. Gukasyan (Institute of Botany, National Academy of Sciences of Armenia, Erevan, Armenia), and Dr. N.K. Aminov (Institute of Genetic Resources of Azerbaijan, Baku, Azerbaijan) for providing the material for this investigation. Our work was supported by grants from the Russian State Foundation of Basic Research, the program 'Dynamics and Conservation of Genepools', and a DFG grant (HO1779/23-1). N.P.G. is grateful for the support from the State Budget Project No. VI.53.1.1.

\section{References}

-Badaeva ED, Badaev NS, Gill BS, Filatenko AA: Intraspecific karyotype divergence in Triticum araraticum (Poaceae). Plant Syst Evol 192:117-145 (1994).

Badaeva ED, Friebe B, Gill BS: Genome differentiation in Aegilops. 2. Physical mapping of $5 \mathrm{~S}$ and 18S-26S ribosomal RNA gene families in diploid species. Genome 39:1150-1158 (1996a).

Badaeva ED, Friebe B, Gill BS: Genome differentiation in Aegilops. 1. Distribution of highly repetitive DNA sequences on chromosomes of diploid species. Genome 39:293-306 (1996b).

Badaeva ED, Amosova AV, Muravenko OV, Samatadze TE, Chikida NN, et al: Genome differentiation in Aegilops. 3. Evolution of the D-genome cluster. Plant Syst Evol 231:163190 (2002).

- Badaeva ED, Amosova AV, Samatadze TE, Zoshchuk SA, Shostak NG, et al: Genome differentiation in Aegilops. 4. Evolution of the U-genome cluster. Plant Syst Evol 246: 45-76 (2004).

- Badaeva ED, Budashkina EB, Bilinskaya EN, Pukhalskiy VA: Intergenomic chromosome substitutions in wheat interspecific hybrids and their use in the development of a genetic nomenclature of Triticum timopheevii chromosomes. Russ J Genet 46:769-785 (2010a).

- Badaeva ED, Shelukhina OY, Diederichsen A, Loskutov IG, Pukhalskiy VA: Comparative cytogenetic analysis of Avena macrostachya and diploid C-genome Avena species. Genome 53:125-137 (2010b).

-Badaeva ED, Zoshchuk SA, Paux E, Gay G, Zoshchuk NV, et al: Fat element - a new marker for chromosome and genome analysis in the Triticeae. Chromosome Res 18:697-709 (2010c).

- Bardsley D, Cuadrado A, Jack P, Harrison G, Castilho A, Heslop-Harrison JS: Chromosome markers in the tetraploid wheat Aegilops ventricosa analysed by in situ hybridization. Theor Appl Genet 99:300-304 (1999).
Bedbrook RJ, Jones J, O’Dell M, Thompson RJ, Flavell RB: A molecular description of telomeric heterochromatin in Secale species. Cell 19:545-560 (1980)

Bowden WM: The taxonomy and nomenclature of the wheats, barleys and ryes and their relatives. Can J Bot 37:657-684 (1959).

Brandolini A, Vaccino P, Boggini G, Özkan H, Kilian B, Salamini F: Quantification of genetic relationships among A genomes of wheats. Genome 49:297-305 (2006).

Cuadrado A, Schwarzacher T, Jouve N: Identification of different chromatin classes in wheat using in situ hybridization with simple sequence repeat oligonucleotides. Theor Appl Genet 101:711-717 (2000).

Cuadrado A, Cardoso M, Jouve N: Physical organisation of simple sequence repeats (SSRs) in Triticeae: structural, functional and evolutionary implications. Cytogenet Genome Res 120:210-219 (2008).

Damania AB, Valkoun J, Willcox G, Qualset CO (eds): The Origins of Agriculture and Crop Domestication, p 345 (ICARDA, Aleppo 1998).

Dorofeev VF, Filatenko AA, Migushova EF, Udachin RA, Jakubziner MM: Cultivated flora of the USSR. 1. Wheat, p 346 (Kolos, Leningrad 1979).

Dubcovsky J, Dvořák J: Ribosomal RNA multigene loci: nomads of the Triticeae genomes. Genetics 140:1367-1377 (1995).

Dvoř́k J, Diterlizzi P, Zhang HB, Resta P: The evolution of polyploid wheats - identification of the A-genome donor species. Genome 36: 21-31 (1993).

Feldman M: Origin of cultivated wheat, in Bonjean AP, Angus WJ (eds): The World Wheat Book: A History of Wheat Breeding, pp 3-56 (Tec \& Doc/Intersept Ltd., London-ParisNew York 2001).

Friebe B, Gill BS: Chromosome banding and genome analysis in diploid and cultivated polyploid wheats, in Jauhar PP (ed): Methods in Genome Analysis in Plants: Their Merits and Pitfals, pp 39-60 (CRC Press, New York 1996).
Friebe B, Kim NS, Kuspira J, Gill BS: Genetic and cytogenetic analyses of the A genome of Triticum monococcum. VI. Production and identification of primary trisomics using the C-banding technique. Genome 33:542-555 (1990).

Friebe B, Mukai Y, Gill BS: C-banding polymorphism in several accessions of Triticum tauschii (Aegilops squarrosa). Genome 35:192199 (1992).

Gerlach WL, Bedbrook JR: Cloning and characterization of ribosomal RNA genes from wheat and barley. Nucleic Acids Research 7: 1869-1885 (1979).

- Gerlach WL, Dyer TA: Sequence organization of the repeated units in the nucleus of wheat which contains 5S-rRNA genes. Nucleic Acids Res 8:4851-4865 (1980).

Heun M, Schäfer-Pregl R, Klawan D, Castagna R, Accerbi M, et al: Site of einkorn wheat domestication identified by DNA fingerprinting. Science 278:1312-1314 (1997).

Huang S, Sirikhachornkit A, Su X, Faris J, Gill B, et al: Genes encoding plastid acetyl-CoA carboxylase and 3-phosphoglycerate kinase of the Triticum/Aegilops complex and the evolutionary history of polyploid wheat. Proc Natl Acad Sci USA 99:8133-8138 (2002).

Jaaska V: Electrophoretic survey of seedling esterases in wheats in relation to their phylogeny. Theor Appl Genet 56:273-284 (1980).

-Jiang J, Gill BS: Different species-specific chromosome translocations in Triticum timopheevii and T. turgidum support the diphyletic origin of polyploid wheats. Chromosome Res 2:59-64 (1994a).

Jiang J, Gill BS: New 18S-26S ribosomal RNA gene loci: chromosomal landmarks for the evolution of polyploid wheats. Chromosoma 103:179-185 (1994b).

-Komuro S, Endo R, Shikata K, Kato A: Genomic and chromosomal distribution patterns of various repeated DNA sequences in wheat revealed by a fluorescence in situ hybridization procedure. Genome 56:131-137 (2013). 
Konarev VG: Wheat Proteins, p 351 (Kolos, Moscow 1980).

Konovalov F, Goncharov N, Goryunova S, Shaturova A, Proshlyakova T, Kudryavtsev A: Molecular markers based on LTR retrotransposons BARE-1 and Jeli uncover different strata of evolutionary relationships in diploid wheats. Mol Genet Genomics 283:551-563 (2010).

Kubaláková $M$, Kovářová $P$, Suchánková $P$, Č́ihalíková J, Bartoš J, et al: Chromosome sorting in tetraploid wheat and its potential for genome analysis. Genetics 170:823-829 (2005).

Kubis S, Schmidt T, Heslop-Harrison JS: Repetitive DNA elements as a major component of plant genomes. Ann Bot 82:45-55 (1998).

Kuz'menko SP, Ataeva DM, Gandilyan PA: Comparative investigation of diploid wheats by means of C-banding technique. Rus J Genet 23:686-692 (1987)

Ling HQ, Zhao SC, Liu DC, Wang JY, Sun H, et al: Draft genome of the wheat A-genome progenitor Triticum urartu. Nature 496:87-90 (2013).

-Liu CJ, Atkinson MD, Chinoy CN, Devos KM, Gale MD: Nonhomoeologous translocations between group 4, 5 and 7 chromosomes within wheat and rye. Theor Appl Genet 83:305312 (1992).

-Megyeri M, Farkas A, Varga M, Kovács G, Molnár-Láng M, Molnár I: Karyotypic analysis of Triticum monococcum using standard repetitive DNA probes and simple sequence repeats. Acta Agron Hung 60:87-95 (2012).

Mukai Y, Nakahara Y, Yamamoto M: Simultaneous discrimination of the three genomes in hexaploid wheat by multicolor fluorescence in situ hybridization using total genomic and highly repeated DNA probes. Genome 36: 489-494 (1993).

-Nagaki K, Tsujimoto H, Isono K, Sasakuma T: Molecular characterization of a tandem repeat, Afa family, and its distribution among Triticeae. Genome 38:479-486 (1995).

-Novak P, Neumann P, Macas J: Graph-based clustering and characterization of repetitive sequences in next-generation sequencing data. BMC Bioinformatics 11:378 (2010).
Pedersen C, Langridge P: Identification of the entire chromosome complement of bread wheat by two-colour FISH. Genome 40:589-593 (1997).

Rayburn AL, Gill BS: Molecular identification of the D-genome chromosomes of wheat. I Hered 77:253-255 (1986a).

Rayburn AL, Gill BS: Isolation of a D-genome specific repeated DNA sequence from Aegilops squarrosa. Plant Mol Biol Rep 4:104-109 (1986b).

Rayburn AL, Gill BS: Molecular analysis of the Dgenome of the Triticeae. Theor Appl Genet 73:385-388 (1987).

-Salina EA, Adonina IG, Vatolina TY, Kurata N: A comparative analysis of the composition and organization of two subtelomeric repeat families in Aegilops speltoides Tausch. and related species. Genetica 122:227-237 (2004).

-Salina EA, Lim YK, Badaeva ED, Scherban AB, Adonina IG, et al: Phylogenetic reconstruction of Aegilops section Sitopsis and the evolution of tandem repeats in the diploids and derived wheat polyploids. Genome 49:10231035 (2006a).

Salina EA, Leonova IN, Efremova TT, Roder MS: Wheat genome structure: translocations during the course of polyploidization. Funct Integr Genomics 6:71-80 (2006b).

-Schneider A, Linc G, Molnar-Lang M: Fluorescence in situ hybridization polymorphism using two repetitive DNA clones in different cultivars of wheat. Plant Breeding 122:396400 (2003).

-Sepsi A, Molnár I, Szalay D, Molnár-Láng M: Characterization of a leaf rust-resistant wheat - Thinopyrum ponticum partial amphiploid BE-1, using sequential multicolor GISH and FISH. Theor Appl Genet 116:825-834 (2008). Singh K, Chhuneja P, Kaur S, Kaur S, Garg T, et al: Triticum monococcum: a source of novel genes for improving several traits in hexaploid wheat, in Appels R, Eastwood R, Lagudah E, Langridge $\mathrm{P}$, Mackay M, McIntyre L, Sharp P (eds): Proceedings of the 11th International Wheat Genetics Symposium, pp 295-297 (Sidney University Press, Sidney 2008).
Taketa S, Harrison GE, Heslop-Harrison JS: Comparative physical mapping of the $5 \mathrm{~S}$ and 18S-25S rDNA in nine wild Hordeum species and cytotypes. Theor Appl Genet 98:1-9 (1999).

Taketa S, Ando H, Takeda K, Harrison GE, Heslop-Harrison JS: The distribution, organization and evolution of two abundant and widespread repetitive DNA sequences in the genus Hordeum. Theor Appl Genet 100:169-176 (2000).

Taketa S, Ando H, Takeda K, Von Bothmer R: Physical locations of 5S and 18S-25S rDNA in Asian and American diploid Hordeum species with the I genome. Heredity 86:522-530 (2001).

Taketa S, Ando H, Takeda K, Ichii M, Von Bothmer R: Ancestry of American polyploid Hordeum species with the I genome inferred from 5S and 18S-25S rDNA. Ann Bot 96:23-33 (2005).

Tang Z, Yang Z, Fu S: Oligonucleotides replacing the roles of repetitive sequences pAs1, pSc119.2, pTa-535, pTa71, CCS1, and pAWRC.1 for FISH analysis. J Appl Genetics 55:313-318 (2014).

Tavrin EV: To the origin of a species $T$. zhukovskyi Men. et Er. Bulletin of Applied Botany, Genetics and Breeding 3b:89-96 (1964).

Upadhia MD, Swaminathan MS: Studies on origin of T. zhukovslyi and on the mechanisms regulating chromosome pairing in Triticum. Indian J Genet Pl Br 25:1-12 (1969).

Van Slageren MW: Wild Wheats: A Monograph of Aegilops L. and Amblyopyrum (Jaub. \& Spach) Eig (Poaceae), p 514 (Wageningen Agricultural University, Wageningen and ICARDA, Aleppo 1994).

Zohary D, Hopf M: Domestication of Plants in the Old World, ed 3, p 316 (Oxford University press, Oxford 2001).

Zoshchuk S, Badaeva E, Zoshchuk N, Adonina I, Shcherban' A, Salina E: Intraspecific divergence in wheats of the Timopheevi group as revealed by in situ hybridization with tandem repeats of the Spelt1 and Spelt52 families (in Russian). Russ J Genet 43:636-645 (2007). 